\title{
The effect of dietary fat on the fatty acid composition and cholesterol content of the eggs from Hy-line and Warren hens
}

\author{
By M.J. González-Muñoz, ${ }^{*}$ S. Bastida, ${ }^{2}$ O. Jiménez, ${ }^{2}$ C. Lorenzo de ${ }^{3}$ G. Vergara ${ }^{3}$ \\ and F.J. Sánchez-Muniz ${ }^{2}$
}

\author{
${ }^{1}$ Departamento de Nutrición y Bromatología. Facultad de Farmacia, Universidad de Alcalá. \\ Alcalá de Henares, Madrid, Spain. \\ ${ }^{2}$ Departamento de Nutrición y Bromatología I (Nutrición). \\ Facultad de Farmacia, Universidad Complutense. Madrid, Spain. \\ ${ }^{3}$ Instituto Madrileño de Investigación Agraria y Alimentaria. Madrid. Spain \\ ( ${ }^{\star}$ Corresponding author: mariajose.gonzalez@uah.es)
}

\section{RESUMEN}

La grasa dietética afecta al contenido de ácidos grasos y colesterol del huevo de gallinas Hy-line and Warren.

El objetivo del presente estudio fue analizar los efectos de la grasa de la dieta de dos estirpes de ponedoras (Hy-line y Warren) sobre el contenido de ácidos grasos y colesterol del huevo durante un periodo del ciclo de puesta de 20 meses. Ambas estirpes recibieron 3 dietas consecutivas que contenían $7 \%$ de lípidos de los cuales $3 \%$ provenía de los componentes basales de la dieta y $4 \%$ fue adicionado en forma de grasa, aceites u oleínas con objeto de aumentar progresivamente el contenido de ácidos grasos poliinsaturados y disminuir el contenido de los ácidos grasos saturados y monoinsaturados. El cambio de grasa en la dieta afectó al perfil de la mayoría de los ácidos grasos del huevo, sugiriéndose la existencia de un mínimo de ácido elaídico en la grasa añadida para su aparición en el huevo. El contenido de AGP se incrementó mientras que el de AGM disminuyó en el huevo a lo largo del estudio. El contenido de colesterol fue mas elevado con la mezcla de grasa animal/aceite de soja que con la grasa animal o con la mezcla oleica/aceite de soja. La grasa añadida a la dieta más que la estirpe de ponedora influyó sobre la composición de ácidos grasos el cociente AGS/AGP contenido de colesterol e índices aterogénicos y trombogénicos.

PALABRAS CLAVE: Ácidos grasos - Colesterol - Estirpe de ponedora - Huevo - Índice aterogénico - Índice trombogénico.

\section{SUMMARY}

The effect of dietary fat on the fatty acid composition and cholesterol content of Hy-line and Warren hen eggs.

The present study analyzed the effect of dietary fat and strain on the fatty acid and cholesterol contents of eggs over a 20 month-period. Hy-line and Warren hens received three consecutive $7 \%$ lipid diets in which the basal constituents of the diet supplied $3 \%$ of the fats while the remaining $4 \%$ was composed of fats, oils or oleins added to progressively increase polyunsaturated fatty acid (PUFA) levels, while decreasing dietary levels of both saturated fatty acids (SFA) and monounsaturated fatty acids (MUFA). In general, the percentages of most fatty acids in egg lipids were affected by changes in dietary lipids but not by the strain. Data suggest the existence of a dietary threshold for elaidic acid to appear in eggs. Mufa decreased and total PUFA increased throughout the study. The cholesterol egg content was higher at the animal fat plus soybean oil than at the animal fat or the olein plus soybean oil blend. Overall, results showed that changes in dietary lipids influenced fatty acid composition and hence atherogenic and thrombogenic indexes much more than the strain.

KEY-WORDS: Atherogenic index - Cholesterol - Egg composition - Fatty acids - Hen-strain - Thrombogenic index.

\section{INTRODUCTION}

For years, eggs have been considered a powerhouse of nutrition, due to their content in exceptionally high quality proteins and essential nutrients (Elkin, 2006); however, they are also a significant source of dietary cholesterol (Applegate, 2000). An alternative way to reduce the potential cholesterolaemic effect of eggs is to modify the fatty acid composition of the yolks (Elkin, 2006). The cholesterol-lowering effects of polyunsaturated fatty acids (PUFA) have been recognized for some years (Naber and Biggert, 1989), and feeding egg layers a diet rich in PUFA results in higher relative and absolute concentrations of PUFA in yolk total lipids (Jiang and Sim, 1992). In chickens, yolk cholesterol can be influenced by breed or strain (Chowdhury et al, 2002) or age of the hen (Vorlova et al., 2001); nonetheless, information on the influence of strain and age on egg fatty acid composition throughout the laying cycle is controversial (Elkin, 2006).

The fatty acid profile of eggs varies substantially depending on the supplement fed (Van Elswyk, 1997). Some relevant studies have suggested that trans fatty acids, mostly elaidic acid, exert a deleterious effect on the lipoprotein metabolism (Mensink and Katan, 1990; Lichtenstein et al., 1999). However, few studies have shown the influence of dietary trans fatty acid (e.g. elaidic acid) intake on egg trans fatty acid content. Several reports (Combs and Helbacka, 1960, Summer et al. 1966) demonstrated that the quantity and type of fatty acids present in the diet could also influence egg yolk cholesterol content, although the 
hen's response to the amount and saturation of dietary lipids varied somewhat among studies.

Two strains of laying hens were selected for their prolific egg production: Hy-line hens, whose eggs are white and lay more eggs although of a slightly smaller size and Warren hens, whose eggs are brown. Taking into account all these previous premises, we hypothesise that strain, age and dietary fat composition exert a relevant effect on egg composition. Therefore, the objectives of the present study are to analyze, over 20 months of the laying period, 1) the effect of the progressive decrease in dietary trans fatty acids and increase in PUFA n-6 and n-3 fatty acids on egg fatty acid composition and cholesterol content; 2) the differences in the response of Warren and Hy-line strains to these dietary modifications.

\section{MATERIALS AND METHODS}

\subsection{Animals and diets}

One hundred and fifty Hy-line and the same number of Warren 23- week-old laying hens from a poultry farm near Madrid (Spain) were selected and housed at the rate of 6 birds per cage throughout the study. Hens of both strains were fed a diet containing $7 \%$ fat (W/W) during the entire study. The basal dietary ingredients, expressed as $\mathrm{kg} / 100 \mathrm{~kg}$ were: Spanish corn, 21.8\%; sunflower flour (37\% weight), $12 \%$; meat meal (45-50\% protein), 6\%; corn distillers dried grains (DDGS), 10\%; pearl barley plus enzymes, $31.9 \%$; soya (44\% weight), $4.9 \%$; $\mathrm{CaCO}_{3}, 4,5 \% ; \mathrm{CaPO}_{4} \mathrm{H}, 2.5 \% ; \mathrm{NaCl}, 1 \%$; other minerals, $0.4 \%$; vitamin premix and choline $1 \%$; added fat or olein, $4 \%$. Oleins from beef and pork tallows were also purchased from RIOSA (Linares, Jaén, Spain). While oils and oleins constituted $57.9 \%$ of the total dietary fat, the components of the basal diet mentioned above constituted the remaining $42.1 \%$. The study lasted 20 months. During the first four-month dietary period hens received a diet containing animal fat (beef and pork tallows) (AF). The second dietary period, which lasted 6 months, included a homogenous mix of AF and soybean oil (AF-SO). A homogeneous blend of oleins and soybean oil (O-SO) was employed in the 10-month-long third period. As all hens were fed the three diets, and one diet served as a control for the others. No additional control group to be fed a homogeneous diet throughout the entire study was considered necessary.

\subsection{Egg sampling}

Eighteen 60-65 g eggs were selected at random from each strain every two months, which implied 2 , 3 and 5 samplings during the AF, AF-SO and O-SO periods, respectively. The egg-weight criterion could not be met by Hy-line hens during the first (AF) period, when most of their eggs weighed less than $60 \mathrm{~g}$. A total of 10 samplings were taken. From the 18 eggs in each sampling, three eggs were selected at random and weighed and their shells, yolks and whites were separated and weighed. Aliquots of homogenized yolks were weighed and freeze-dried. Freeze-dried samples were kept under nitrogen atmosphere and at $-20{ }^{\circ} \mathrm{C}$ until analysis.

\subsection{Lipid determination}

Egg lipid content was determined according to the Bligh and Dyer (1959) method.

\subsection{Fatty acid determination}

The fat added to the diet and the yolk fat extracts were saponified and methylated according to the IUPAC (1987) method. Methyl esters were determined by gas liquid chromatography (SánchezMuniz et al., 2003). Methyl esters were quantified using tricosanoic acid as internal standard.

\subsection{Cholesterol determination}

The extraction of non-saponifiable matter was carried out with a direct saponification (with previous extraction of lipids) procedure, according to Van Elswyk et al (1991). The cholesterol content was determined by HPLC in a Perkin Elmer liquid chromatograph (USA) equipped with a UV detector. Quantification of cholesterol was performed according to the method of Cores et al., (1995).

\subsection{Fat lipogenesis and quality indexes}

The oleic acid/stearic acid ratio (cis-18:1, n9/18:0) and the arachidonic acid/linoleic acid ratio (cis 20:4, n-6/cis C18:2, n-6) were used as markers of the delta- 9 desaturase and delta- 6 desaturase/ elongase/delta-5 desaturase activities, respectively (Leikin and Brenner, 1987). PUFA/SFA and n-6 PUFA/n-3 PUFA ratios, a modification of the cholesterol-saturated fatty acid index (CSI) of Connor et al (1986), the atherogenic index (AI) and the thrombogenic index (TI) (Di Lorenzo et al., 2001) were used for assessing egg lipid quality.

\subsection{Statistics}

To examine the effect of dietary fat and strain, a two-way ANOVA was carried out with these two main factors and their interaction term. Mean values for the different treatment diets were compared within each strain using the Bonferroni multiple range test (SPSS software 15.0; Chicago, IL).

\section{RESULTS}

\subsection{Diet}

The fatty acid content of the fat added to the diets is shown in Table 1. The degree of unsaturation of 
Table 1

Fatty acid composition ( $\mathrm{g} / 100 \mathrm{~g}$ fat) of the fat added to the diet during the different dietary experimental periods

\begin{tabular}{|c|c|c|c|}
\hline Fat source & $\begin{array}{l}\text { AF period } \\
\text { Tallow }\end{array}$ & $\begin{array}{l}\text { AF-SO Period } \\
\text { Tallow and soybean }\end{array}$ & $\begin{array}{l}\text { O-SO period } \\
\text { Olein and soybean }\end{array}$ \\
\hline Caprilic (C8:0) & $0.01(0.02)^{a}$ & $0.01(0.01)^{a}$ & $0.07(0.05)^{b}$ \\
\hline Capric (C10:0) & $0.05(0.01)^{a}$ & $0.03(0.01)^{a}$ & $N^{b}$ \\
\hline Lauric (C12:0) & $0.11(0.01)^{a}$ & $0.06(0.00)^{b}$ & $\mathrm{ND}^{\mathrm{c}}$ \\
\hline Myristic (C14:0) & $2.14(0.06)^{a}$ & $1.16(0.05)^{b}$ & $0.13(0.04)^{c}$ \\
\hline Pentadecanoic (C15:0) & $0.15(0.22)^{a}$ & $0.08(0.11)^{a}$ & $0.02(0.03)^{a}$ \\
\hline Palmitic (C16:0) & $21.32(0.12)^{\mathrm{a}}$ & $16.18(0.14)^{b}$ & $9.70(0.09)^{c}$ \\
\hline isomer C16:1 & $0.38(0.01)^{a}$ & $0.20(0.01)^{b}$ & $0.02(0.02)^{c}$ \\
\hline Palmitoleic (C16:1 n-7) & $2.88(0.08)^{a}$ & $1.53(0.04)^{b}$ & $0.21(0.00)^{c}$ \\
\hline Margaric $(C 17: 0)$ & $0.80(0.06)^{a}$ & $0.48(0.05)^{b}$ & $0.14(0.05)^{\mathrm{c}}$ \\
\hline Margaroleic (C17:1) & $0.53(0.06)^{a}$ & $0.28(0.03)^{b}$ & $0.05(0.01)^{c}$ \\
\hline Stearic (C18:0) & $12.87(0.05)^{a}$ & $8.51(0.05)^{b}$ & $3.83(0.03)^{c}$ \\
\hline Elaidic (trans C18:1, n-9) & $2.77(0.03)^{a}$ & $1.43(0.02)$ & $0.29(0.02)$ \\
\hline Oleic (cis C18:1, n-9) & $33.35(1.24)^{a}$ & $27.50(0.68)^{b}$ & $27.22(0.04)^{b}$ \\
\hline C18:1, n-7 & $2.23(0.15)^{a}$ & $1.89(0.18)^{\mathrm{ab}}$ & $1.45(0.17)^{b}$ \\
\hline cis 9. trans 12 Linoelaidic & $N^{a}$ & $\mathrm{ND}^{\mathrm{a}}$ & $0.09(0.05)^{b}$ \\
\hline cis 12. trans-9 Linoelaidic & $0.27(0.02)^{a}$ & $0.14(0.01)^{b}$ & $0.05(0.02)^{c}$ \\
\hline Linoleic (cis C18:2, n-6) & $7.89(0.49)^{a}$ & $29.53(0.40)^{b}$ & $45.67(0.20)^{c}$ \\
\hline Arachidic (C20:0) & $0.81(0.80)^{a}$ & $0.70(0.51)^{a}$ & $0.84(0.17)^{a}$ \\
\hline$\gamma$-linolenic (cis 18:3, n-6) & $0.05(0.00)^{a}$ & $0.02(0.00)^{b}$ & $N^{c}$ \\
\hline$\alpha$-Linolenic (cis 18:3, n-3) & $0.81(0.02)^{a}$ & $3.95(0.08)^{b}$ & $4.54(0.08)^{c}$ \\
\hline N-eicosaenoic (C20:1) & $0.50(0.01)^{a}$ & $0.37(0.01)^{b}$ & $0.24(0.01)^{c}$ \\
\hline Eicosadienoic (C20:2, n-6) & $0.22(0.01)^{a}$ & $0.11(0.00)^{b}$ & $\mathrm{ND}^{\mathrm{c}}$ \\
\hline Eicosatrienoic (C20:3, n-6) & $0.08(0.01)^{a}$ & $0.04(0.00)^{b}$ & $N^{c}$ \\
\hline Arachidonic acid (C20:4, n-6) & $0.04(0.01)^{a}$ & $0.02(0.00)^{b}$ & $0.01(0.00)^{c}$ \\
\hline Eicosapentaenoic (C20:5, n-3) & $\mathrm{ND}^{\mathrm{a}}$ & $N^{a}$ & $0.03(0.04)^{b}$ \\
\hline Behenic (C22:0) & $N^{a}$ & $0.21(0.03)^{b}$ & $0.53(0.03)^{c}$ \\
\hline Docosapentaenoic (C22:5, n-3) & $N^{a}$ & $N D^{a}$ & $0.02(0.03)^{a}$ \\
\hline Docosahexaenoic (C22:6, n-3) & $0.02(0.02)^{a}$ & $0.01(0.01)^{a}$ & $0.02(0.03)^{a}$ \\
\hline Lignoceric (C24:0) & $N^{a}$ & $0.12(0.02)^{b}$ & $0.33(0.04)^{c}$ \\
\hline Total SFA & $38.27(1.35)^{a}$ & $28.97(1.01)^{b}$ & $15.13(0.50)^{c}$ \\
\hline Total MUFA & $42.64(1.58)^{a}$ & $35.20(1.01)^{b}$ & $29.64(0.27)^{c}$ \\
\hline Total PUFA & $9.30(0.55)^{a}$ & $35.83(0.53)^{b}$ & $50.69(0.45)^{c}$ \\
\hline Total PUFA n-3 & $0.81(0.02)^{a}$ & $4.18(0.09)^{b}$ & $4.61(0.15)^{c}$ \\
\hline Total PUFA n-6 & $8.50(0.53)^{a}$ & $31.64(0.44)^{b}$ & $46.08(0.30)^{c}$ \\
\hline PUFA n-6/PUFA n-3 & $9.82(0.87)^{a}$ & $8.02(0.94)^{a}$ & $12.73(1.34)^{b}$ \\
\hline SFA/PUFA & $3.83(0.28)^{a}$ & $0.93(0.27)^{b}$ & $0.29(0.07)^{\mathrm{c}}$ \\
\hline
\end{tabular}

AF: Animal fat; AF-SO: Animal fat and soybean oil blend; O-SO: Olein and soybean oil. SFA: saturated fatty acids, MUFA: monounsaturated fatty acids; PUFA: polyunsaturated fatty acids. Mean values (SD) of three determinations bearing a different letter are significantly different (ANOVA $p<0.05)$

the diet increased progressively, as SFA oils and oleins were substituted primarily by PUFA, and to a lesser extent by MUFA. Percentages of linoleic and $\alpha$-linolenic acids in the added fat increased more than 5-fold throughout the study. The fat added to the basal components in the AF period was rich in palmitic and oleic acids, but also contained $2.77 \%$ elaidic acid. During the AF-SO dietary period, palmitic and oleic acid levels in the added fat were lower, while linoleic and linolenic acid levels were higher. The fat added during the O-OS period was similar to that of the AF-SO period but contained a lower SFA content and higher linoleic and linolenic acid levels.

\subsection{Weight and fat content}

A significant strain-dietary fat interaction was found on egg $(p<0.01)$ and yolk $(p<0.001)$ weights. Egg and yolk weights were affected by strain $(p<0.001)$ and the type of fat added ( $p<$ $0.001)$. Hy-line hens laid the lowest weight eggs during the $1^{\text {st }}$ experimental period. There was no significant interaction between strain and the type of added fat on egg fat content. Fat content of the eggs did not differ significantly due to strain or dietary period (Table 2).

\subsection{Fatty acid and cholesterol contents and fat quality indexes}

A significant interaction between egg type and the type of added fat was found only for palmitoleic and elaidic acids ( $p<0.001$ ) (Table 2). Dietary period affected the levels of most fatty acids in the eggs but white and brown eggs displayed no significant differences with regard to many fatty acids within each period of the study. Hy-line eggs 
THE EFFECT OF DIETARY FAT ON THE FATTY ACID COMPOSITION AND CHOLESTEROL CONTENT...

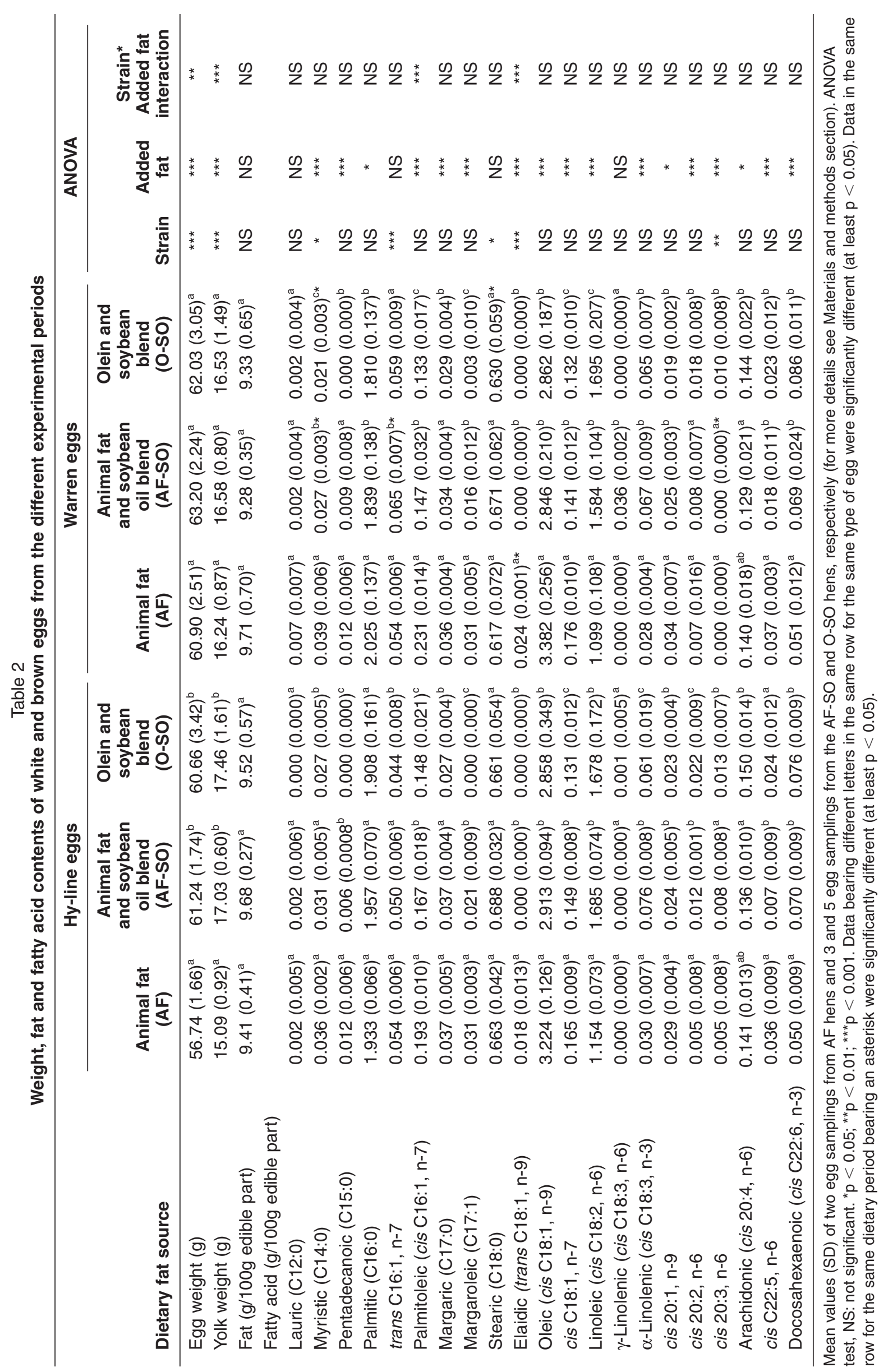




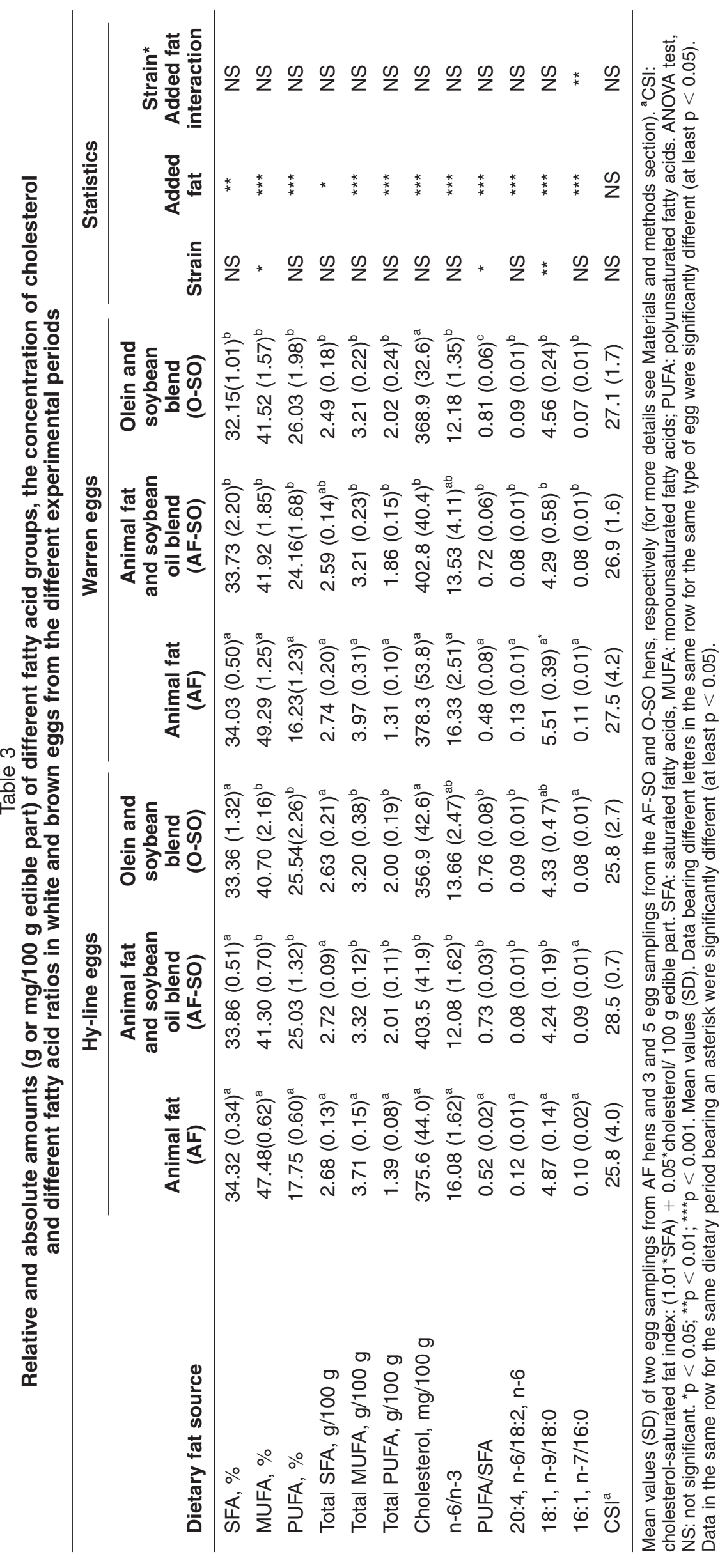


contained higher amounts of myristic, stearic and eicosatrienoic acids, but lower levels of transpalmitoleic and elaidic acids (Table 2).

Cholesterol was affected by the type of fat added ( $p<0.001$ ) but not by strain (Table 3 ). During the O-SO dietary period (10 months) egg cholesterol content was lower than that of the AFSO period, although both egg strains displayed relatively large variations during the O-SO period. (Fig. 1)

The percentage of MUFA and the PUFA/SFA ratio were lower in white eggs while no differences were found between white and brown eggs for the absolute amounts of SFA, MUFA and PUFA and the $n-6 / n-3$ ratio. The dietary period significantly affected (at least, $p<0.05$ ) all these parameters (Table 3). The arachidonic acid/linoleic acid, oleic acid/stearic acid and palmitoleic acid/palmitic acid ratios decreased during the $\mathrm{AF}-\mathrm{SO}$ and $\mathrm{O}-\mathrm{SO}$ periods. The oleic acid/stearic acid ratio was lower only during the AF diet in Hy-line eggs ( $p<0.05$ ). The CSI index was not affected by strain or dietary period (Table 3).

Figures 2 and 3 show the influence of the added dietary fat and the strain on the atherogenic and thrombogenic indexes of egg fat. There were significant interactions between strain and dietary period $(p<0.01)$. The type of the added fat affected $(p<0.001)$ both indexes.

\section{DISCUSSION}

\subsection{Egg weight}

Peblees et al. (2000) indicated that egg weight increased progressively with hen age. The eggs laid by the Hy-line hens during the AF period weighed less than $60 \mathrm{~g}$, thereby explaining the significant interaction observed between the strains and dietary periods. Nonetheless, this effect was no longer observed in the eggs of Hy-line hens after the $27^{\text {th }} w \mathrm{w}$. This finding indicates that Warren hens lay larger eggs than Hy-line hens at an early age. Hy-line hens are smaller than Warren hens which explains, at least in part, these results.

It has been reported that dietary unsaturated fatty acids increase egg weight by modifying oviduct protein synthesis (Whitehead et al., 1991). However, the present data suggest that the degree of unsaturation of the added fat did not affect egg and yolk weights during the last two dietary periods. Grobas et al. (1999) indicated that supplemental fat in the diet consistently improved the productivity of hens and egg weight and that the linolenic acid requirement for maximum productivity was $1.15 \%$ or less. Accordingly, the amount of linolenic acid in the added fat during the last dietary period, approximately $0.3 \%$, was adequate. Grobas et al. (2001) found that linseed and soybean oil diets

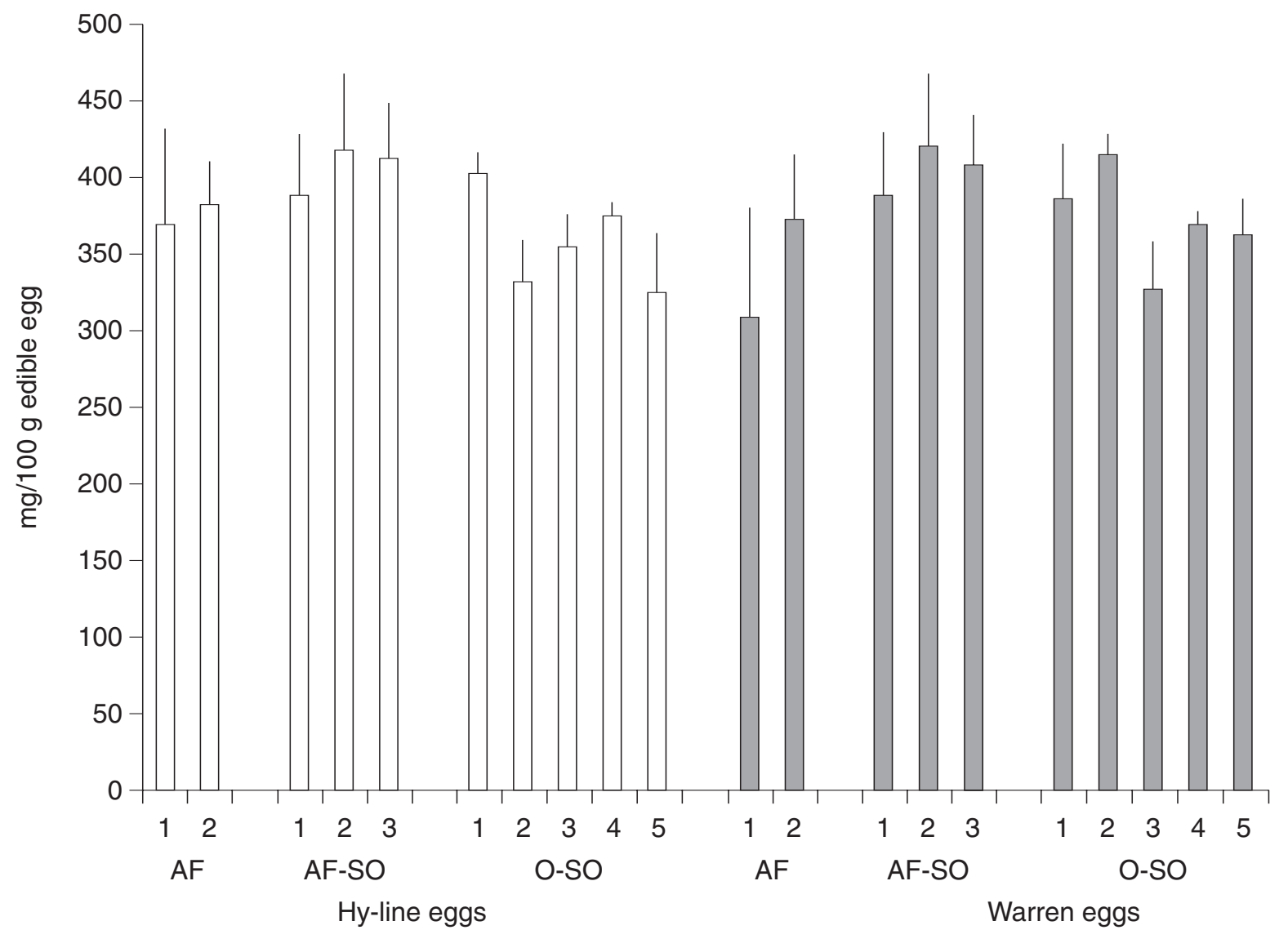

Figure 1

Changes in cholesterol content (mean + SD) of Hy-line (white bars) and Warren eggs (grey bars) throughout the study. AF, animal-fat diet period; AF-SO: animal fat and soybean oil blend (50:50, V/V) period; O-SO: soybean oil and olein blend (50:50, V/V) period. Numbers in the different periods correspond to the samplings performed. 


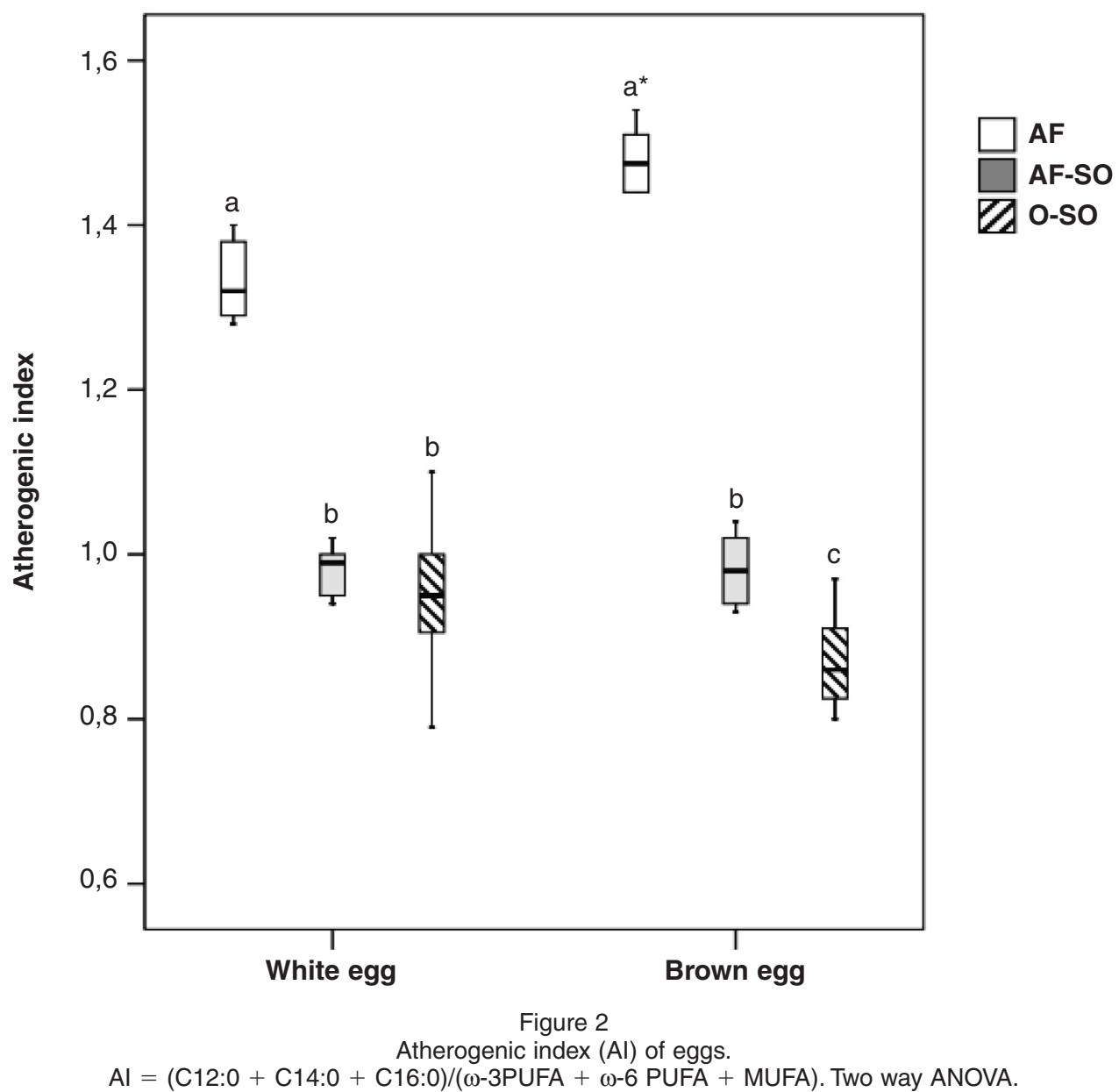

Hen Strain*dietary period interaction $(p<0.01)$. Data bearing different letters for the same type of egg were significantly different (at least $p<0.05$ ). Data for the same dietary period bearing an asterisk were significantly different (at least $p<0.05)$.

produced greater egg mass than diets based on tallow or olive oil in two strains of laying hens. Egg weight may also be related to the elaidic acid dietary content, because egg mass was uniformly lower in hens fed a CLA-enriched diet (Szymczyk \& Pisulewsky, 2003).

\subsection{Egg fat and fatty acid contents}

In agreement with Hargis et al. (1991) and Kuksis (1992), the egg lipid content throughout the present study did not change significantly in either strain, regardless of diet and/or hen age. Despite the important decrease in SFA in the fat added to the diet throughout the study, only the absolute amount of SFA and that of palmitic acid decreased in brown eggs. These data suggest strain differences in response to dietary saturation. However, the actual reasons are yet unknown. Naber \& Biggert (1989) suggested that large amounts of SFA in the diet $(>10 \%)$ are needed to increase the content of SFA in eggs. Pardio et al. (2005) found that the concentration of SFA in eggs generally remained at a constant level, even when the proportion of dietary soybean soapstock increased.

Current results show that the egg level of elaidic acid is related to dietary elaidic fatty acid content; however, a minimum elaidic acid content of $1.5 \%$ of the total fatty acids in the added fat seems necessary to detect this trans fatty acid in eggs. Yin et al (2008) found a significant effect of layer breed performance on egg composition due to an enrichment of the CLA isomer and fatty acids in yolk lipids in response to dietary CLA. Results on elaidic acid are interesting, taking into account present concerns regarding the presence of trans fatty acid in the diet. Dietary energy contribution of such fatty acids has to be less than $1 \%$ due to their negative effect on LDL-cholesterol and HDL-cholesterol (Mensink and Katan, 1990; Lichtenstein et al., 1999). Present results suggest that the elaidic acid in a portion of two AF eggs would constitute about $0.1 \%$ of the daily total energy consumption.

Grobas et al (2001) found that white eggs present a higher SFA content and lower MUFA and PUFA levels than brown eggs. In the present study the reduction of MUFA in the fat added to the diet decreased the egg MUFA content, while the increase in dietary PUFA increased their proportion of PUFA. However, except for the relative content of MUFA, which was higher during the AF dietary period in white eggs, no differences related to strain were found. The decrease observed in MUFA content was similar to that reported by other 


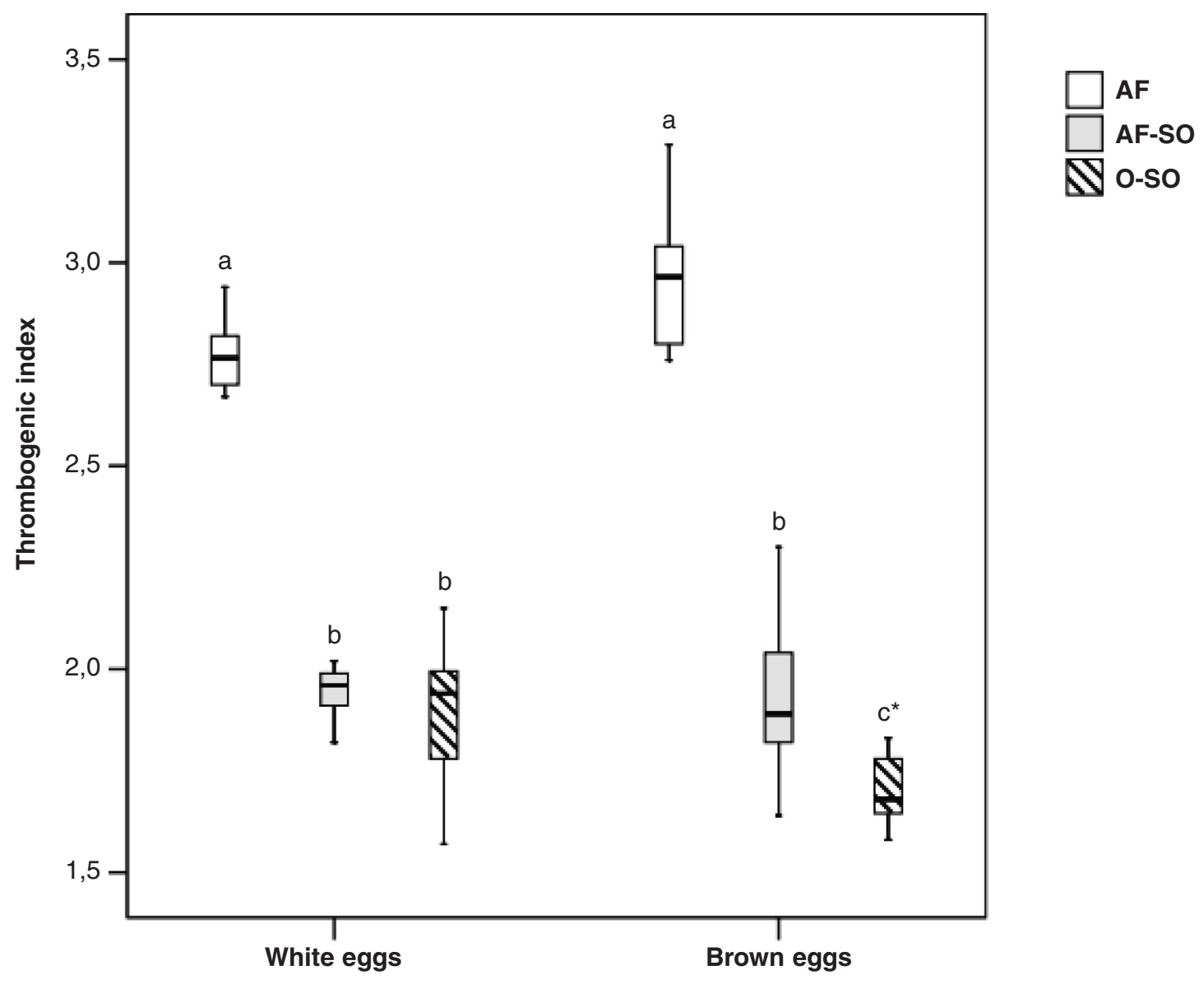

Figure 3

Thrombogenic index (TI) of eggs.

$\mathrm{TI}=(\mathrm{C} 14: 0+\mathrm{C} 16: 0+\mathrm{C} 18: 0) /(0.5 \omega-6$ PUFA $+3 \omega-3$ PUFA $+\omega-3$ PUFA/ $\omega-6$ PUFA $)$. Two way ANOVA. Hen strain type*dietary period interaction $(p<0.01)$. Data bearing different letters for the same type of egg were significantly different $($ at least, $p<0.05$.

investigators (Yang et al. 2002; Szymczyk \& Pisulewski, 2003).

Increased levels of linoleic and $\alpha$-linolenic acids in the fat added to the diet significantly increased the concentration of linoleic, $\alpha$-linolenic, and docosahexaenoic (DHA) in white and brown eggs, although the levels of arachidonic and docosapentaenoic acids decreased during the AFSO dietary period. In general terms, the further increase in dietary linoleic and $\alpha$-linolenic acids during the O-SO dietary period did not greatly affect the long PUFA content in eggs. Grobas et al. (2001) found that docosapentaenoic and DHA in the eggs increased when dietary $\alpha$-linolenic acid increased.

Baucells et al. (2000) found that small proportions of fish oil in diets resulted in lower SFA values and higher $n-6$ fatty acid levels. The $n-6$ content increased mostly because of the rise in linoleic acid, although the level of arachidonic acid was always higher when fish oil was completely suppressed. Moreover, only diets supplemented with linseed oil produced eggs with measurable amounts of eicosapentaenoic acids. In the present study, eicosapentanoic acid was not detected in eggs because the diet contained about $0.06 \%$ in $\alpha$ linolenic acid during the AF period and about $0.3 \%$ during the AF-SO and O-SO periods.
Pardio et al (2005) evaluated the effect of soybean soapstock on hen egg fatty acid composition and their results show a similar percentage of total SFA and total MUFA throughout their experiment; the total and especially long-chain PUFA n-3 content increased. Present results from the two periods in which soybean oil was added to the diet showed an inverse trend for MUFA and PUFA contents.

In the eggs of laying hens fed red crabmeat, the $n-6 / n-3$ ratio values were lower than those of the control group (Grobas et al. 2001). The $n-6 / n-3$ ratios in eggs of the last two dietary periods were lower than those of the AF period, a finding which is probably related to the greater amount of linolenic acid in the fats added to constitute the AF-SO and O-SO diets.

The oleic acid/stearic acid and palmitoleic acid/palmitic acid ratios decreased as a direct consequence of the dietary changes; mostly in the brown eggs. However, changes also were related to the n-3 content of the diets. Garg et al. (1988) demonstrated that both linseed oil and fish oil diets inhibited delta-9 desaturase activity in rat liver microsomes. Synthesis of $n-7$ series monounsaturated fatty acids (palmitoleic and vaccenic acids) decreased with a linseed oil diet but 
increased with a fish oil diet. A fish oil diet produced lower 18:1 n-9 levels in microsomal membrane lipids than a beef tallow diet. Linoleic acid is converted into arachidonic acid by desaturases and elongases (Grynberg, 2005). Present results suggest that the increased level of unsaturation and the higher n-3 PUFA levels in the added fat decreased the conversion of linoleic acid into arachidonic acid in eggs, particularly during the AFSO period. Garg et al. (1990) found that diets containing linseed or fish oil inhibit delta 6desaturase activity. Fish oil inhibition was higher than that of linseed oil when the hens' diets contained high amounts of SFA. However, present results indicate that differences in linoleic acid levels between AF-SO and O-SO diets were not enough to increase conversion of linoleic acid into arachidonic acid.

Similarly, $n-3$ fatty acid levels as $\alpha$-linolenic, eicopentaenoic, docosapentaenoic and DHA in eggs were higher after feeding hen $n-3$ fatty acids with tallow than with safflower oil suggesting that the efficacy of $n-3$ fatty acids in reducing arachidonic acid levels depends on the dietary linolenic acid/SFA ratio (Garg et al 1992). Present results concur with those findings, as arachidonic acid content only decreased in eggs when the added fat contained more $\alpha$-linolenic acid together with high SFA levels (AF-SO diet). This effect was not seen in the O-SO diet, which included lower levels of SFA.

Different variables, such as trans fatty acids, cholesterol and age, negatively affect delta-6 desaturase activity (Sánchez-Muniz, 2003). The increase in egg cholesterol content during the AFSO dietary period may be related to the lower linoleic acid/arachidonic acid ratio observed in eggs during this period. The increase in DHA observed throughout the study must be related to the increase in the linoleic acid content of the added fat and the transformation of this fatty acid into DHA. Warren eggs tended to have more DHA than Hyline eggs, although the difference was not significant. Garg et al. (1992) found low arachidonic levels and increased DHA acid content in rat microsomes using a diet containing n-3 fatty acids. Several studies have found an increase in egg DHA due to dietary $\alpha$-linolenic acid increase (Grobas et al. 2001; Hargis et al. 1991).

\subsection{Cholesterol content and the atherogenic and thrombogenic ratios}

It has been reported that the yolk cholesterol content fluctuated rather irregularly and showed great variability (CV 9.7-18.2\%) throughout the laying period (Ingr et al, 1987). Present results (changes $>10 \%$ ) could be, partially, a consequence of this variability; however, because the results of each period were an average of several samples, the changes in cholesterol content should be mainly related to changes in dietary fat. In fact, an increase was found during the AF-SO period (Fig. 1) suggesting that high levels of unsaturated fat in the added fat stimulated cholesterol synthesis in the liver and increased cholesterol storage in the eggs. However, the opposite was observed when the AFSO and the O-SO periods were compared (Fig. 1). Intensive market egg production was found to be associated with decreases in yolk cholesterol content (Ingr et al., 1987). Moreover, because period 3 lasted 10 months, the effect of ageing on egg cholesterol content must not be ruled out.

As the atherogenic and thrombogenic ratios are thought to be fat quality markers (Di Lorenzo et al., 2001), the changes observed in those indexes suggest a better fat quality of the eggs produced during the last two dietary periods (Fig. 2 and 3).

\section{CONCLUSIONS}

The fat added to the basal diet, and to a much lesser degree the strain of the laying hens, affected the fatty acid content of the eggs. The decrease of SFA and the increase of PUFA in the added fat resulted in slight changes in egg SFA and MUFA profiles and contents, and more important changes in egg PUFA levels. Data suggest that at least 1.5\% of elaidic acid in the added fat is needed to detect such fatty acid in eggs. Changes in egg cholesterol levels seem to be a consequence of the fat added to the diet, the age of the laying hen and egg unsaturation but not of the strain.

\section{REFERENCES}

Applegate E. 2000. Introduction: nutritional and functional roles of eggs in the diet. Journal of American College of Nutrition 19 (5 Suppl), 495S-498S.

Baucells MD, Crespo N, Barroeta AC, Lopez-Ferrer S, Grashorn MA. 2000. Incorporation of different polyunsaturated fatty acids into eggs. Poultry Science 79, 51-59.

Bligh EG, Dyer WJ. 1959. A rapid method of total lipid extraction and purification. Canadian Journal of Biochemistry and Physiology 37, 911-917.

Combs GF, Helbacka NV. 1960. Studies with laying hens. I. Effect of dietary fat, protein levels and other variables in practical rations. Poultry Sciences 39, 271-279.

Connor SL, Gustafson JR, Artaud-Wild SB, Flawell DP, Classick-Kohn CJ, Hatcher LF, Connor WE 1986. The cholesterol/saturated-fat index: An indication of hypercholesterolemic and atherogenic potential of food. Lancet 1, 1229-1232.

Cores A, Vergara G, De Lorenzo C. 1995 Cholesterol levels in commercial eggs in Madrid (Spain) determined by an HPLC procedure, in Cerero R, $(\mathrm{Ed})$ Egg and Egg Product Quality. Instituto de Investigación Agraria y Alimentaria, Madrid, pp. 395403.

Chowdhury SE, Chowdhury SD, Smith TK. 2002. Effects of dietary garlic on cholesterol metabolism in laying hens. Poultry Science 81, 1856-1862.

Di Lorenzo A, Petroni ML, De Luca PP, Andreoli A, Morini P, Jacopino L, Innocente J, Perriello G. 2001. Use of 
Quality control indices in moderately hypocaloric Mediterranean diet for treatment of obesity. Diabetes Nutrition and Metabolism 14, 181-188.

Elkin RG. 2006. Reducing shell egg cholesterol content. I. Overview, genetic approaches, and nutritional strategies. World's Poultry Science Journal 62, 665-687.

Garg ML, Wierzbicki AA, Thomson AB, Clandinin MT. 1988. Dietary cholesterol and/or n-3 fatty acid modulate delta-9 desaturase activity in rat liver microsomes. Biochemical and Biophysical Acta 962, 330-336.

Garg ML, Thomson ABR, Chandinin HT. 1990. Interactions of saturated, $n-6$ and $n-3$ polyunsaturated fatty acids to modulate arachidonic acid metabolism. Journal of Lipid Research 31, 271-277.

Garg ML, Keelan M, Thomson ABR, Clandinin MT. 1992. Desaturation of linoleic acid in the small bowel is increased by short-term fasting and by dietary content of linoleic acid. Biochemical and Biophysical Acta 1126, 17-25.

Grobas S, Mendez J, De Blas C, Mateos GG. 1999. Laying hen productivity as affected by energy, supplemental fat, and linoleic acid concentration of the diet. Poultry Science 78, 1542-1551.

Grobas S, Mendez J, De Blas C, Mateos GG. 2001. Influence of source and percentage of fat added to diet on performance and fatty acid composition of egg yolks of two strains of laying hens. Poultry Science $\mathbf{8 0}$, 1171-1179.

Grynberg A. 2005. Hypertension prevention: from nutrients to (fortified) foods to dietary patterns. Focus on fatty acids. Journal of Human Hypertension 19, S25-S33.

Hargis PS, Van Elswyk ME, Hargis BM. 1991. Dietary modification of yolk lipid with menhaden oil. Poultry Science 70, 874-883.

Ingr I, Simeonova J, Stavkova J, Petrovsky E, Dostal F. 1987. Cholesterol content in market hen eggs. Nahrung 31, 933-940.

IUPAC. 1987 Standard methods for analysis of oil, fats and derivatives, in Paquot $C$, Hatfenne A (Eds). $7^{\text {th }}$ revised and enlarged edition. Blackwell Scientific, Publications Oxford, pp. 123-129.

Jiang Z, Sim JS. 1992. Effects of dietary n-3 fatty acidenriched chicken eggs on plasma and tissue cholesterol and fatty acid composition of rats. Lipids 27,279-284.

Kuksis A. 1992. Yolk lipids. Biochemical and Biophysical Acta 25, 1124:205-222.

Leikin Al, Bremer RR. 1987. Cholesterol-induced microsomal changes modulate desaturase activities. Biochemical and Biophysical Acta, 922, 294-303.

Lichtenstein AH, Ausman LM, Jalbert SM, Schaefer EJ. 1999. Effects of different forms of dietary hydrogenated fats on serum lipoprotein cholesterol levels. New England Journal of Medicine 340, 1933-1940.

Mensink RP, Katan MB. 1990. Effect of dietary trans fatty acids on high-density and low-density lipoprotein cholesterol levels in healthy subjects. New England Journal of Medicine 323, 439-445.
Naber EC, Biggert MD. 1989. Pattern of lipogenesis in laying hens fed a high fat diet containing safflower oil. Journal of Nutrition 119, 690-695.

Pardio VT, Landin LA, Waliszewski KN, Perez-Gil F, Diaz L, Hernandez B. 2005. The effect of soybean soapstock on the quality parameters and fatty fat acid composition of hen egg yolk. Poultry Science 84,148157.

Peebles ED, Zumwatl CD, Doyle SM, Gerard PD, Latour MA, Boyle CR, Smith TW. 2000. Effects of breeder age and dietary fat source and level on broiler hatching egg characteristics. Poultry Science 79, 698704.

Sánchez-Muniz FJ. 2003. Lípidos, in García Arias MT, García Fernández MC (Eds) Nutrición y Dietética, Universidad de León. Spain, pp. 119-133.

Sánchez-Muniz FJ, García-Linares MC, García-Arias MT, Bastida S, Viejo J. 2003. Fat and protein from olive oilfried sardines interact to normalize serum lipoproteins and reduce liver lipids in hypercholesterolemic rats. Journal or Nutrition 133, 2302-2308

Summers JD, Slinger SJ, Anderson WJ. 1966. The effect of feeding various fats and fat by-products on the fatty acid and cholesterol of eggs. British Poultry Science 7, 127-134.

Szymczyk B, Pisulewski PM. 2003. Effects of dietary conjugated linoleic acid on fatty acid composition and cholesterol content of hen egg yolks. British Journal of Nutrition 90, 93-99.

Van Elswyk ME, Schake LS, Hargis PS. 1991. Evaluation of two extraction methods for the determination of egg yolk cholesterol. Poultry Science 70, 1258-1260.

Van Elswyk ME. 1997. Comparison of n-3 fatty acid sources in laying hen rations for improvement of whole egg nutritional quality: a review. British Journal of Nutrition 78 (Suppl. 1), S61-S69.

Vilchez C, Touchburn SP, Chavez ER, Chan CW. 1991. Effect of feeding palmitic, oleic, and linoleic acids to Japanese quail hens (Coturnix coturnix japonica). 1. Reproductive performance and tissue fatty acids. Poultry Science 70, 2484-93

Vorlova L, Sieglova E, Karpiskova R, Kopriva V. 2001. Cholesterol content in eggs during the laying period. Acta Veterinaria Brno 70, 387-390.

Whitehead CC, Bowman AS, Griffin HD. 1991. The effects of dietary fat and bird age on the weights of egg components in the laying hen. British Poultry Science 32, 565-574

Yang L, Huang Y, James AE, Lam LW, Chen ZY. 2002. Differential incorporation of conjugated linoleic acid isomers into egg yolk lipids. Journal of Agricultural and Food Chemistry 50, 4941-4946.

Ying JD, Shang XG, Li DF, Wang FL, Guan YF, Wang ZY. 2008. Effects of dietary conjugated linoleic acid on the fatty acid profile and cholesterol content of egg yolks from different breeds of layers. Poultry Science 87, 284-290. 